\title{
Abatement of p-Nitrophenol from Aqueous Solutions Using Oxidized Carbon Fiber
}

\author{
Shaymaa E. El-Shafey, Nady A. Fathy*, Laila B. Khalil \\ Physical Chemistry Department, National Research Centre, 33 El Bohouth Street \\ (former Tahrir st.), Dokki, P.O. 12622, Giza, Egypt.
}

\begin{abstract}
$\mathbf{T}$
WO oxidized carbon fibers (o-CF and o-CF-400) with microporous structure and surface area as high as $\sim 1500-1130 \mathrm{~m}^{2} / \mathrm{g}$ were prepared from commercial carbon fiber felt to be used as good carbon adsorbents for removing highly toxic organic pollutant. The obtained oxidized CF samples were characterized by SEM, $\mathrm{N}_{2}$ adsorption isotherms at $-196^{\circ} \mathrm{C}$ as well as Boehm's titration and FTIR techniques. Removal of p-nitrophenol (p-NP), as a probe organic pollutant existed in wastewater of various industries, was studied in a batch mode. Kinetic and equilibrium adsorption studies were investigated and found that the adsorption data of p-NP molecules were well-fitted with pseudo-second-order model and Langmuir isotherm. Based on the porosity developed in oxidized CFs, p-NP molecules are mostly accommodated onto micropores. An oxidized carbon fiber, o-CF showed the higher removal of $\mathrm{p}-\mathrm{NP}$ than that obtained using o-CF-400 due to its high micropore surface area $\left(1450 \mathrm{~m}^{2} / \mathrm{g}\right)$. It was clearly observed that the adsorption of p-NP depended remarkably on the surface area of carbon fibers. It was found that values of monolayer adsorption capacity obtained by application of Langmuir equation were 258 and $155 \mathrm{mg} / \mathrm{g}$ using o-CF and o-CF-400 adsorbents, respectively, at $25^{\circ} \mathrm{C}$ and $\mathrm{pH}$ 4. Finally, it can be concluded that the both oxidized carbon fibers can be emerged as effective adsorbents because they exhibited a great adsorption capability in removing organic pollutants from wastewater.
\end{abstract}

Keywords: Carbon fiber, Oxidation, Porosity, Adsorption, p-nitrophenol.

\section{Introduction}

Phenolic compounds are widely used as ingredients and solvents in many industries such as petrochemicals, pharmaceuticals, pesticides, plastics, etc. These were classified as hazardous chemical pollutants and designated as priority chemicals by the Environmental Protection Agency in the USA $[1,2]$. The discharge of such pollutants into water bodies can cause severe threats to the environment, aquatic life and human due to their high toxicity and resistant to biodegradation as well as they create bad taste and odour in the water.

Among these phenolic pollutants, paranitrophenol ( $p-N P)$ is one of the famous and toxic organic contaminants as classified by United States Environmental Protection Agency [3]. It has been reported that high levels of PNP were $60 \mu \mathrm{g} / \mathrm{L}$ in drinking water [2]. Thus there is a priority to minimize the concentration of $\mathrm{p}-\mathrm{NP}$ in wastewater and for this reason there is an upsurge of interest in improving and implementing technologies for removing $\mathrm{p}$-NP. In this context, many traditional methods to remove $\mathrm{p}$-NP from aqueous solutions have been studied such as adsorption [4], chemical oxidation [5,6], microbial degradation [7], membrane filtration [8] and electrochemical treatment [9].

However up-to-date, adsorption onto carbon materials is the most widely used technology due to it is easy operation, cost-effective and can be applied simply in treating large volumes of domestic and industrial effluents. Through recent literature, there are different carbon materials that have been employed as efficient adsorbents for removal of $\mathrm{p}$-NP from aqueous solutions, for example; activated carbons [10], reduced graphene oxide [11], carbon nanotubes [12], activated carbon cloth [13] and activated carbon fiber [14]. The adsorption capacity of a given carbon toward phenolic compounds is considerably depended on its porous structure, chemical nature of the surface and $\mathrm{pH}$ of the aqueous solution [15]. Regarding the adsorption of various substituted phenols, factors of their physical and chemical natures 
affect the adsorption capacity of carbons such as molecular dimensions (i.e. weight, volume and diameter), solubility and $\mathrm{pK}$ of adsorbed phenols [16]. Daifullah and Girgis [16] reported that the uptake of some phenols increased according to the increase in their molecular dimensions and acidity and to the decrease in their solubility as the following order: phenol $<$ $\mathrm{m}$ - or p-cresol $<2$-chlorophenol $<4$-nitrophenol $<2$,4-dinitrophenol $<2$,4-dichlorophenol.

By comparing to granular or powdered activated carbons, carbon fibers or activated carbon fibers possess many preferable properties like larger specific surface area (as high as $2500 \mathrm{~m}^{2} / \mathrm{g}$ ), superior bulk volume lead to fast mass transfer rate, higher mechanical integrity, easy handling in the form of felt or cloth to be used as filters, and finally they have lower diffusion limitation to adsorption in a batch adsorber $[13,14]$.

Fibrous structure of carbon fiber materials was originally derived from electrospinning or meltspinning route of various polymer precursors such as rayon, polyacrylonitrile (PAN), pitches, lignin-blended synthetic polymer, etc. [17, 18]. Among these polymeric precursors, PAN is considered to be the most common polymer precursor mainly due to (i) its high carbon yield and flexibility for tailoring the final structure of carbon fibers and (ii) its stabilization can be done easily owing to the formation of a ladder structure via nitrile polymerization [18] and hence about $90 \%$ of the commercially available carbon fibers produced worldwide are PAN-derived. In manufacture of PAN-carbon fiber, stabilization process was carried out by a slow heating of an PAN-fiber precursor in air to $300^{\circ} \mathrm{C}$ so as to make the fibers thermoset via cross-linking, and then followed by a carbonization at elevated temperatures $>1000^{\circ} \mathrm{C}$ to convert the stabilized fibers to carbon fiber. Also, the carbonization process was usually carried out in an inert gas atmosphere like nitrogen, helium or argon to prevent oxidation of carbon [18]. The surface modification of carbon fibers is very important procedure to increase their surface heterogeneity to prepare carbon fiber composites with excellent mechanical properties. For example, the surface oxidation can introduce many oxygen surface groups such as hydroxyl, carboxyl, carbonyl, lactone, quinone, etc., which improve not only the surface properties of carbon fibers but also the adsorption characteristics of these materials.

Egypt.J.Chem. 60 , No.6 (2017)
Based on the reported literature above, the present work aims at evaluating the adsorption capacity of oxidized carbon fibers prepared from chemical oxidation of commercial carbon fiber felt either by nitric acid treatment (o$\mathrm{CF}$ ) or by nitric acid followed by post-heat treatment of o-CF at $400^{\circ} \mathrm{C}$ for $30 \mathrm{~min}$ to give o-CF-400. The prepared oxidized carbon fibers were characterized by SEM, $\mathrm{N}_{2}$ adsorption/ desorption isotherms applying the BET equation and the $\alpha_{\mathrm{s}}$ - method as well as Boehm's titration and FTIR to identify the variety of oxygen functional groups. The p-nitrophenol (p-NP) as a target pollutant was used to investigate the adsorption behavior under varying in the initial concentration of $\mathrm{p}-\mathrm{NP}$, contact time and $\mathrm{pH}$ of $\mathrm{p}$-NP solution in a batch mode using the prepared adsorbents. To analyze the adsorption process of p-NP onto the prepared samples, kinetic models, e.g. pseudo-first-order, pseudosecond order and intraparticle diffusion models were used as well as equilibrium isotherms such as Langmuir, Freundlich and Temkin were tested.

\section{Experimental}

\section{Preparation of carbon fiber adsorbents}

Commercial carbon fiber felt with $10 \mathrm{~mm}$ of thickness used in this study was manufactured from PAN-based by Flag Advertising Ltd., China. This felt was cut into small pieces of $5 \mathrm{~mm} \times 5 \mathrm{~mm}$. nitric acid oxidation of CF was carried out according to the following procedure: $3 \mathrm{M}$ of $\mathrm{HNO}_{3}$ acid $(400 \mathrm{~mL})$ was added slowly to $10 \mathrm{~g}$ of $\mathrm{CF}$ under vigorous stirring at $80^{\circ} \mathrm{C}$ for 4h. After that, the CF in nitric acid solution was left overnight at ambient temperature. The vessel contents were diluted with water and filtered. The carbon was washed with distilled water until neutral $\mathrm{pH}$ and separated by filtration. It was finally dried in an air oven at $80^{\circ} \mathrm{C}$ overnight and the treated sample was called oxidizedcarbon fiber "o-CF". An additional sample was produced from pos-heat treatment of o-CF at $400^{\circ} \mathrm{C}$ in a static air for $30 \mathrm{~min}$. To attach this temperature, the fiber was put inside a crucible dish and heated slowly (heating rate $10^{\circ} \mathrm{C} / \mathrm{min}$ ) in an electrical muffle under static air. The mass of initial sample was decreased about $40 \%$ and the final product was labelled as "o-CF-400". The goal of this treatment was to investigate the effect of thermal treatment on the physicochemical and adsorption characteristics of the oxidized-carbon fiber. 


\section{Characterization tools}

The surface structure of the prepared samples was estimated by field-emission scanning electron microscope (SEM) (FE-SEM, FEI Quanta FEG250). Evaluation of porous textures was carried out using nitrogen adsorption-desorption analysis at $-196^{\circ} \mathrm{C}$ (BEL-Sorp, Microtrac Bel Crop, Japan). The adsorption data were analyzed by applying several established procedures in order to get various texture characteristics of the adsorbents under consideration as follows: (i) surface area by the BET-method $\left(\mathrm{S}_{\mathrm{BET}}, \mathrm{m}^{2} / \mathrm{g}\right)$, and the total pore volume $\left(\mathrm{V}_{\mathrm{p}}, \mathrm{cm}^{3} / \mathrm{g}\right)$ from the volume adsorbed at a relative pressure of 0.95 . An estimate for the average pore diameter was calculated by $\bar{r}(\AA)$ $=4 \mathrm{~V}_{\mathrm{p}} / \mathrm{S}_{\mathrm{BET}} \times 10^{4}$ [19]. The $\alpha_{\mathrm{s}}$-plot was established by Selles-Perez and Martin-Martinez [20]. This plot was constructed by plotting the adsorbed volume of $\mathrm{N}_{2}\left(\mathrm{~V}_{\mathrm{a}}\right)$ against the corresponding standard values of $\alpha_{\mathrm{s}}$ at same relative pressure. Parameters such as the total surface area $\left(\mathrm{S}_{\mathrm{t}}^{\alpha}\right.$, $\mathrm{m}^{2} / \mathrm{g}$ ) was determined from slope of the line connecting the early points to the origin, and the non-microporous surface area $\left(\mathrm{S}_{\mathrm{n}}{ }^{\alpha}, \mathrm{m}^{2} / \mathrm{g}\right)$ from slope of the line connecting the high pressure data (beyond $\sim \alpha_{\mathrm{s}}=1.0$ ) were estimated. Extrapolation of the latter linear section to meet the $\mathrm{V}_{\mathrm{a}}$-axis represents the volume within micropores $\left(\mathrm{V}_{0}^{\alpha}\right.$, $\mathrm{cm}^{3} / \mathrm{g}$ ). To analyze the pore size distributions, the nitrogen gas adsorption data were analyzed using NLDFT method which allows the quantification of both micro- and mesopores [21].

To quantify the amount of oxygen functional groups, the Boehm's titration method [22] was performed. About $50 \mathrm{mg}$ of carbon fiber was added into $50 \mathrm{~mL}$ of each $0.1 \mathrm{M} \mathrm{NaOH}$ and $\mathrm{HCl}$ aqueous solutions under shaking for $24 \mathrm{~h}$ at room temperature. Then the supernatant solutions were back-titrated with $0.1 \mathrm{M} \mathrm{HCl}$ or $\mathrm{NaOH}$ using phenolphthalein (ph.ph) as an indicator, respectively.

The kind of oxygen surface functional groups formed on the surface of CF samples was investigated by fourier transform infrared (FTIR) spectroscopy in the range of 4000-400 $\mathrm{cm}^{-1}$ using a JASCO 6100 FT-IR spectrometer, and the $\mathrm{KBr}$ disc technique.

\section{Adsorption studies}

Adsorption of p-nitrophenol ( $\mathrm{p}-\mathrm{NP}$ ) onto the oxidized carbon fiber samples was carried out in batch experiments at room temperature $\left(25^{\circ} \mathrm{C}\right)$. To evaluate the optimum $\mathrm{pH}, \mathrm{pH}$ values at $4,6,8$ and
10 were tested for $100 \mathrm{~mL}$ of $\mathrm{p}$-NP solution (150 $\mathrm{mg} / \mathrm{L}$ ) conducted with $100 \mathrm{mg}$ of o-CF sample for $120 \mathrm{~min}$. In kinetic experiments, a weight of 100 $\mathrm{mg}$ of an oxidized $\mathrm{CF}$ adsorbent was added to a $250 \mathrm{~mL}$-conical flask containing $100 \mathrm{~mL}$ of $\mathrm{p}-\mathrm{NP}$ solution. Different initial concentrations of $\mathrm{p}-\mathrm{NP}$ $(100,150$ and $250 \mathrm{mg} / \mathrm{L})$ were prepared and mixed with the prepared sample to carry out adsorption under magnetic stirring at $400 \mathrm{rpm}$ for $4 \mathrm{~h}$, as so as to ensure the occurrence of equilibrium. During each interval time (10-180 $\mathrm{min}$ ), aliquots of 0.2 $\mathrm{mL}$ were withdrawn from the mixture, diluted and filtered through Whatman filter paper No. 41 to measure its final concentration.

To determine the adsorption capacity of prepared oxidized carbon fiber adsorbents, liquid-phase batch adsorption studies towards p-nitrophenol were considered. In each adsorption experiment, $50 \mathrm{~mL}$ of $\mathrm{p}-\mathrm{NP}$ solutions with initial concentrations ranging from 20 to $150 \mathrm{mg} / \mathrm{L}$ were added into a set of $50 \mathrm{~mL}$ conical flasks and conducted with $50 \mathrm{mg}$ solid adsorbent at the optimum $\mathrm{pH}$ of $\mathrm{p}-\mathrm{NP}$ solution. The flasks were kept in a shaker at a speed of $400 \mathrm{rpm}$. After $240 \mathrm{~min}$, the p-NP solutions were separated from the adsorbent by filtration. Subsequently, the absorbance of the remaining concentration of $\mathrm{p}-\mathrm{NP}$ in the aqueous solution was measured at wavelength of $317 \mathrm{~nm}$ using UV-vis spectrophotometer (Shimadzu-PC 2401).

The amount of p-NP adsorbed onto oxidized carbon fiber adsorbents at equilibrium $\left(q_{e}, \mathrm{mg} / \mathrm{g}\right)$ or at time $\mathrm{t}\left(q_{p}, \mathrm{mg} / \mathrm{g}\right)$ was calculated according to the following expressions:

$$
\begin{aligned}
& q_{e}=\frac{\left(C_{0}-C_{e}\right)}{\mathrm{m}} V \\
& q_{t}=\frac{\left(C_{0}-C_{t}\right)}{\mathrm{m}} V
\end{aligned}
$$

where $C_{0}, C_{e}$, and $C_{t}$ are initial, equilibrium and time concentrations $(\mathrm{mg} / \mathrm{L})$ of $\mathrm{p}-\mathrm{NP}$, respectively. $V$ is the volume of solution $(\mathrm{mL})$ and $m$ is the mass of dried adsorbent (mg). The effects of the following parameters on removal of $\mathrm{p}-\mathrm{NP}$ were studied: (i) $\mathrm{pH}$ of $\mathrm{p}-\mathrm{NP}$, (ii) initial $\mathrm{p}-\mathrm{NP}$ concentration $(100-250 \mathrm{mg} / \mathrm{L})$ and contact time $(10-180 \mathrm{~min})$ at a constant temperature $\left(25^{\circ} \mathrm{C}\right)$ and at the optimum $\mathrm{pH} \sim 4$.

\section{Adsorption models}

Three common kinetic models were used in order to investigate the adsorption mechanism of 
p-NP onto an adsorbent. Firstly, the Lagergrenfirst-order kinetic model can be described by the equation [23]:

$$
\log \left(q_{e}-q_{i}\right)=\log q_{e}-\frac{k_{1} t}{2.303}
$$

where $q_{e}$ and $q_{t}$ are the amounts of p-NP adsorbed $(\mathrm{mg} / \mathrm{g})$ at equilibrium and time $\mathrm{t}$ ( $\mathrm{min}$ ), respectively; $k_{1}$ is the rate constant of the Lagergren-first-order kinetic model $\left(\mathrm{min}^{-1}\right)$. The values of $\mathrm{k}_{1}$ were calculated from the plots of $\log \left(\mathrm{q}_{\mathrm{e}}-\mathrm{q}_{\mathrm{t}}\right)$ versus $t$.

Secondly, a linear form of pseudo-secondorder kinetic model was expressed by the equation [24]:

$$
t / q_{t}=\frac{1}{k_{2} q_{e}{ }^{2}}+\frac{t}{q_{e}}
$$

where $\mathrm{k}_{2}$ is the rate constant ( $\mathrm{g} / \mathrm{mg} \mathrm{min}$ ) of pseudosecond-order kinetic model of adsorption. The slope and intercept of the linear plots $\mathrm{t} / \mathrm{q}_{\mathrm{t}}$ against $t$ yield the values of $1 / \mathrm{q}_{\mathrm{e}}$ and $1 / \mathrm{k}_{2} \mathrm{q}_{\mathrm{e}}{ }^{2}$.

Thirdly, an intra-particle mass transfer diffusion model can be described by the equation [25]:

$$
\mathrm{q}_{\mathrm{t}}=k_{i d} \mathrm{t}^{1 / 2}+C
$$

where $k_{i d}$ is the intra-particle diffusion rate constant $\left(\mathrm{mg} / \mathrm{g} \mathrm{min}{ }^{1 / 2}\right)$ and $C(\mathrm{mg} / \mathrm{g})$ is the intercept, which can be calculated from the slope and intercept of the linear plots of $q_{t}$ versus $t^{1 / 2}$, respectively.

To examine the equilibrium adsorption of $\mathrm{p}-\mathrm{NP}$ onto the prepared adsorbents, the adsorption data were analyzed in terms of Langmuir, Freundlich, and Temkin adsorption isotherms. The linear form of the Langmuir isotherm is expressed by the following equation [26]:

$$
\frac{C_{e}}{\boldsymbol{q}_{e}}=\frac{1}{\boldsymbol{K}_{L} \boldsymbol{Q}_{m}}+\frac{1}{\boldsymbol{q}_{m}} C_{e}
$$

where $\mathrm{C}_{\mathrm{e}}$ is the equilibrium concentration of $\mathrm{p}-\mathrm{NP}(\mathrm{mg} / \mathrm{L}), \mathrm{q}_{\mathrm{e}}$ the uptake amount of p-NP at equilibrium $(\mathrm{mg} / \mathrm{g})$, and $\mathrm{q}_{\mathrm{m}}$ is the monolayer adsorption capacity $(\mathrm{mg} / \mathrm{g})$ and $K_{L}(\mathrm{~L} / \mathrm{mg})$ is the Langmuir adsorption equilibrium constant. The free energy of adsorption, $\Delta G(\mathrm{~kJ} / \mathrm{mol})$ can also be evaluated from the parameter $K_{L}$ according to the expression:

$$
\Delta \mathrm{G}=-\mathrm{RT} \ln K_{\mathbf{L}}
$$

In addition Langmuir adsorption isotherm can be given in expression of a dimensionless constant called a "separation factor" and noted as $\left(R_{\mathrm{L}}\right)$ :

$$
R_{L}=\frac{1}{1+C_{o} K_{L}}
$$

The equation representing linear form of Freundlich adsorption can be given as [27]:

$$
\ln q_{\mathrm{e}}=\ln K_{\mathrm{F}}+1 / n \ln C_{\mathrm{e}}
$$

where $\mathrm{K}_{\mathrm{F}}\left(\mathrm{mg} / \mathrm{g}(\mathrm{L} / \mathrm{mg})^{1 / \mathrm{n}}\right)$ is roughly an indicator of the adsorption capacity and $1 / \mathrm{n}$ is the adsorption intensity. Freundlich constants $K_{F}$ and $1 / n$ can be calculated from the intercept and slope of the linear plot with $\ln \mathrm{q}_{\mathrm{e}}$ against $\ln \mathrm{C}_{\mathrm{e}}$.

The linear form of Temkin isotherm is given by [28]:

$$
q_{e}=\mathrm{B}_{1} \ln K_{T}+\mathrm{B}_{1} \ln C_{e}
$$

The constants in equation (10) were defined as $\mathrm{B}_{1}=(\mathrm{RT} / \mathrm{b})$ and $\mathrm{K}_{\mathrm{T}}$ are the Temkin constants. $K_{T}$ is the equilibrium binding constant $(\mathrm{L} / \mathrm{mol})$ corresponding to the maximum binding energy, $\mathrm{b}$ is the variation of adsorption energy $(\mathrm{kJ} / \mathrm{mol})$ and constant $\mathrm{B}_{1}$ is related to the heat of adsorption.

\section{$\underline{\text { Results and Discussion }}$}

\section{Physico-chemical studies}

Figure 1 presents the fibrous structure of the oxidized carbon fiber (o-CF) using SEM. Basically, the o-CF composes of unwoven fibers mat with average diameter of $\sim 8.58 \mu \mathrm{m}$ and apparently smooth surface. Modification of $\mathrm{CF}$ with $\mathrm{HNO}_{3}$ acid has not affected on the morphology of pristine $\mathrm{CF}$ under the prescribed conditions of treatment as shown in the inset image. As well, the post-heat treatment of o-CF at $400^{\circ} \mathrm{C}$ led to a significant contraction throughout the fibrous structure and detected also by the decrease in size and weight of the o-CF felt obtained. The same trend is observed in the evolved porosity of both samples as seen in Fig. 2 and Table 1.

Figure 2 illustrates the adsorption-desorption isotherms of nitrogen gas at $-196^{\circ} \mathrm{C}$ over the prepared CF samples and their corresponding $\alpha_{\text {s }}$ plots. Both samples show a steep increase in the uptake of $\mathrm{N}_{2}$ at relative pressures lower than 0.01 , 
confirming the filling of both narrow micropores (ultra-micropores $<0.7 \mathrm{~nm}$ ) and wide micropores (super-micropores $>0.7 \mathrm{~nm}$ ), however they pose relative external surface area (mesopores accounted 9-22\%) through adsorption of nitrogen over $\mathrm{P} / \mathrm{P}_{0}>0.1$. The obtained adsorptiondesorption isotherms belong to type I of IUPAC classification, which are characteristics of microporous solids. In addition, according to the $\alpha_{\mathrm{s}}$-plots classification provided by Sellez-Perez and Martin-Martinez [20], the given plots (Fig. 2B) correspond to the representative type of " $\alpha 1-$ a». This type is distinguished by having only one linear straight portion parallel to the abscissa axis and starting at $\alpha_{\mathrm{s}}=\sim 1$. Thus the obtained CF samples are essentially microporous with narrow and uniformity micropores. The pore size distributions were analyzed using NLDFT method as seen in the same Fig. 2B (inset image). It was found that the prepared CF samples consist mainly of micropores with almost no mesopores and the maximum pore width was noticed at $1.12 \mathrm{~nm}$ and $1.39 \mathrm{~nm}$ for o-CF and o-CF-400, respectively.

Moreover, the evaluated porous parameters are given in Table 1 . It should be pointed out that the oxidized carbon fibers studied have remarkable differences in their textural properties. For instance, the total surface area and microporosity (i.e. the ratio of micropore volume to total pore volume) developed in the o-CF sample are higher than those evolved in o-CF-400. Accordingly further heat treatment after oxidation of carbon fiber reduces the physico-chemical characteristics including size, fibrous structure and nitrogen adsorption. Clearly, the total surface area and the total pore volume decreased about 25.4 and $17.2 \%$, as a result of the decrease in the microporosity which dropped off also from 90.8 to $78.3 \%$, whereas the mean pore diameter increased about $11.4 \%$ because of widening of micropores after post-heat treatment at $400^{\circ} \mathrm{C}$.

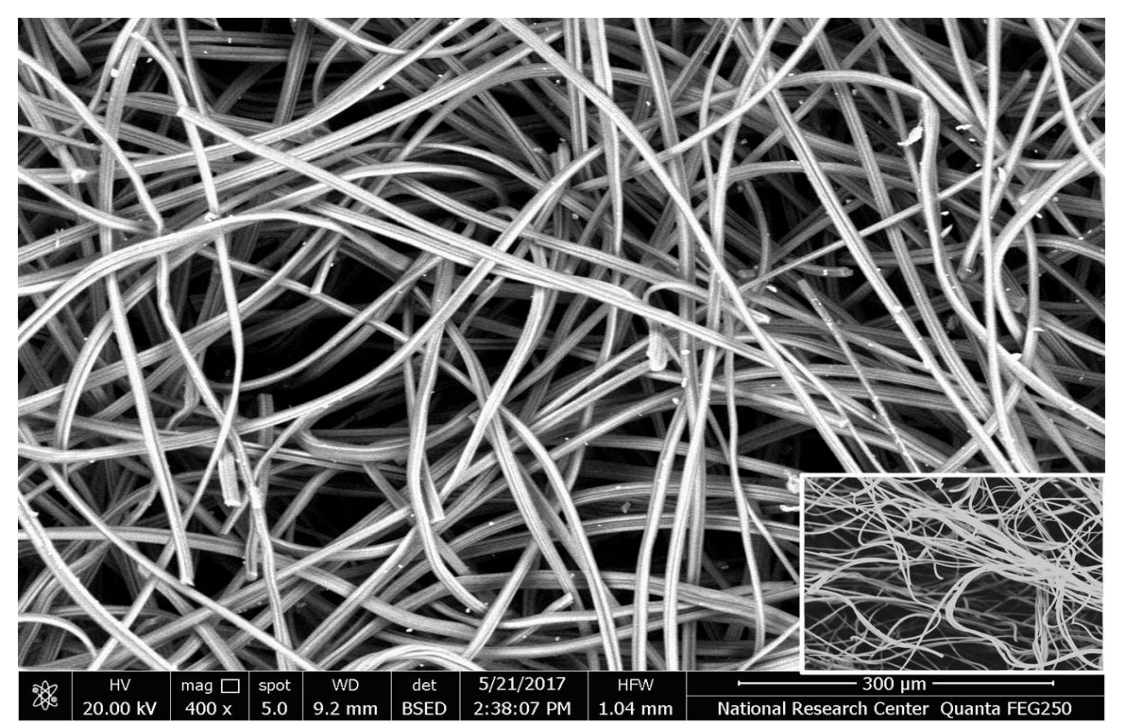

Fig. 1. SEM image of the oxidized carbon fiber (o-CF) (Inset SEM image of o-CF-400).

TABLE 1. Textural parameters of CF samples as accounted from $N_{2}$ adsorption at $-196^{\circ} \mathrm{C}$.

\begin{tabular}{|c|c|c|c|c|c|c|c|c|c|c|}
\hline Samples & $\begin{array}{c}\mathrm{S}_{\mathrm{BET}} \\
\left(\mathrm{m}^{2} / \mathrm{g}\right)\end{array}$ & $\begin{array}{c}V_{\mathrm{p}} \\
\left(\mathrm{cm}^{3} / \mathrm{g}\right)\end{array}$ & $\begin{array}{l}\bar{r} \\
(\AA)\end{array}$ & $\begin{array}{c}S^{\alpha}{ }_{t} \\
\left(m^{2} / g\right)\end{array}$ & $\begin{array}{c}S^{\alpha}{ }^{n} \\
\left(m^{2} / g\right)\end{array}$ & $\begin{array}{c}\mathbf{S}_{\text {mic }}^{\alpha} \\
\left(\mathbf{m}^{2} / \mathbf{g}\right)\end{array}$ & $\begin{array}{c}V^{\alpha} \\
\left(\mathrm{cm}^{3} / \mathrm{g}\right)\end{array}$ & $\begin{array}{c}\mathbf{V}_{0}^{\alpha} / \mathbf{V}_{\mathrm{P}} \\
\mathbf{\%}\end{array}$ & $\begin{array}{c}\text { Total } \\
\text { acidity } \\
(\mathrm{mmol} / \mathrm{g})\end{array}$ & $\begin{array}{c}\text { Total } \\
\text { basicity } \\
\text { (mmol/g) }\end{array}$ \\
\hline $0-C F$ & 1526 & 0.669 & 17.5 & 1602 & 52 & 1450 & 0.606 & 90.6 & 2.86 & 0.11 \\
\hline o-CF-400 & 1133 & 0.554 & 19.5 & 1195 & 135 & 1160 & 0.434 & 78.3 & 3.54 & 0.78 \\
\hline
\end{tabular}



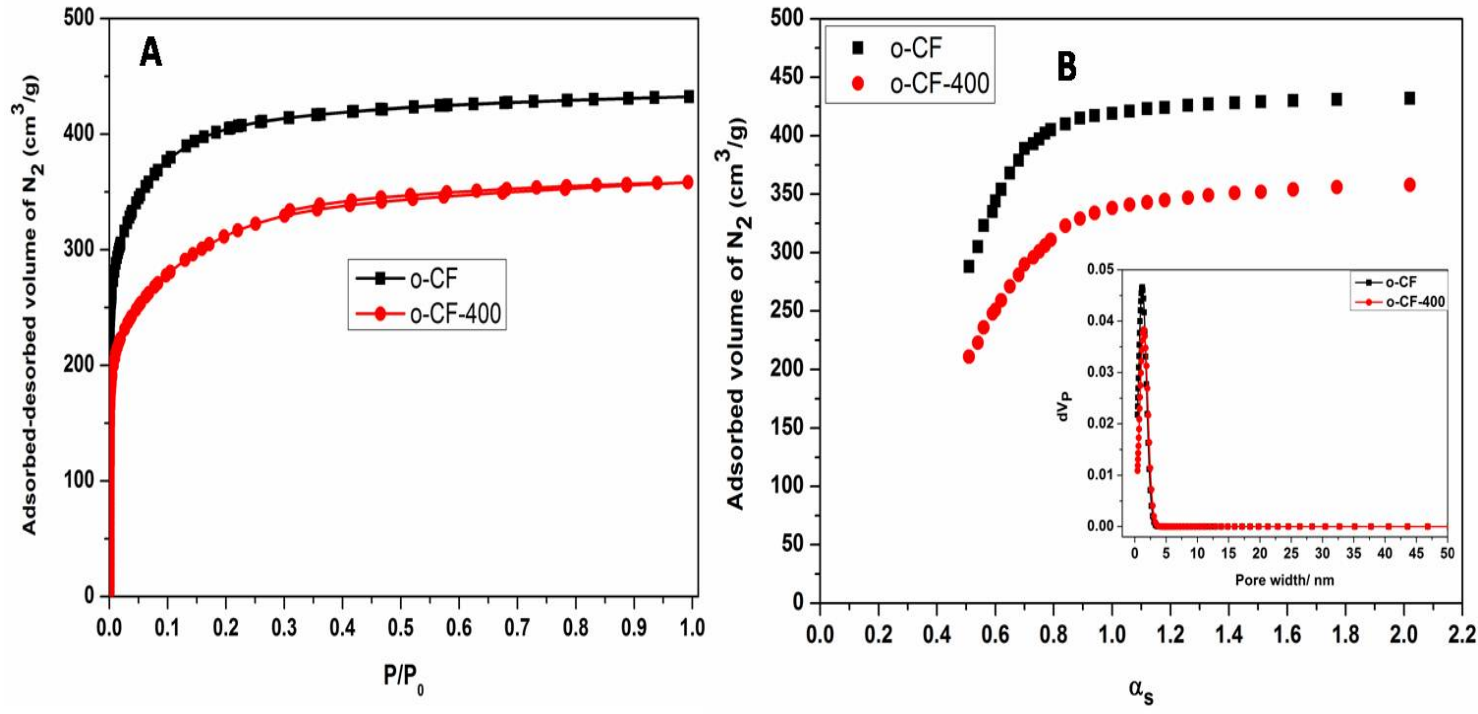

Fig. 2. (A) Adsorption-desorption isotherms of $\mathrm{N}_{2}$ gas at $-196^{\circ} \mathrm{C}$ over the prepared $\mathrm{CF}$ samples and (B) their corresponding $\alpha_{\mathrm{s}}$-plots and pore size distributions by NLDFT method.

The adsorption selectivity of the adsorbent is significantly related to the type and concentration of oxygen-containing functional groups reacted into carbon atoms. By this way, the pristine $\mathrm{CF}$ was pre-oxidized with nitric acid to introduce oxygenated surface groups for forming more surface active sites. In addition, post-heat treatment of oxidized CF sample could decrease the concentration of these functionalities and increase the pore sizes. The results of Boehm's titration are listed in Table 1 and assessed that the o-CF-400 sample contains higher acidic groups and few amount of basic groups than that o-CF sample. Several of oxygen functionalities can be formed according to interaction between oxygen and carbon atoms (i.e. quinone, carbonyl, phenolic, hydroxyl, carboxyl, lactone, and ether) which may be acidic or basic in character. Additionally, the FTIR spectra as shown in Fig. 3 display various oxygen-containing functional groups that appeared with different extents on the surfaces of o-CF and o-CF-400 samples. It can be seen that significant differences occurred in the absorption characteristics of the o-CF sample after heat treatment. Some absorbance bands are broadened and shifted as a consequence of heat treatment. The major oxygen-containing functional groups are: $-\mathrm{OH}$ stretching vibrations in phenol, alcohol and carboxylic groups, $\mathrm{C}=\mathrm{O}$ carbonyl group, $-\mathrm{COO}$ carboxyl group, $-\mathrm{C}-\mathrm{O}-\mathrm{C}$ ether group; besides

Egypt.J.Chem. 60 , No.6 (2017) the presence of nitrogen containing functional groups of $\mathrm{C}=\mathrm{N}$ and $\mathrm{N}-\mathrm{O}$ groups $[28,29]$. Nevertheless, the originated oxygen functional groups from oxidation of the $\mathrm{CF}$ with nitric acid are acidic groups and their absorption intensities are increased slightly after heating at $400^{\circ} \mathrm{C}$ in a static air.

\section{Effect of $p H$}

The adsorption extent of p-NP solutes onto the prepared o-CF adsorbent can be influenced by changing $\mathrm{pH}$ of $\mathrm{p}$-NP from 4 to 8 , thus the effect of $\mathrm{pH}$ on the adsorption amount of $\mathrm{p}$-NP using o-CF is illustrated in Fig. 4. It can be seen that the variation in $\mathrm{pH}$ affects remarkably on the amount of $\mathrm{p}$-NP uptaken by o-CF. The dissociation constant of p-NP $\left(\mathrm{pK}_{\mathrm{a}}\right)$ is $\sim 7.08-7.14$ at $25^{\circ} \mathrm{C}$ [4], and so it exists as molecular form at $\mathrm{pH}<\mathrm{pK}_{\mathrm{a}}$ and as phenoxide anions $\left(\mathrm{C}_{6} \mathrm{H}_{4} \mathrm{O}_{3} \mathrm{~N}\right)^{-}$at $\mathrm{pH}>\mathrm{pK}_{\mathrm{a}}$. Therefore, the adsorption amount of p-NP decreased with increasing $\mathrm{pH}$ values due to the presence of excess hydroxyl ions which competes with the negative charges on the surface of p-nitrophenol molecules. This result is clearly indicative of repulsion electrostatic forces operating during the uptake of $\mathrm{p}-\mathrm{NP}$ at higher $\mathrm{pH}$. These findings in a good agreement with the $\mathrm{pH}$ results obtained previously by Fathy et al. [11] for adsorption of p-NP onto oxidized graphene and reduced graphene oxide adsorbents. Overall, the optimum $\mathrm{pH}$ for adsorption of $\mathrm{p}$-NP onto CFs was found at 4. 


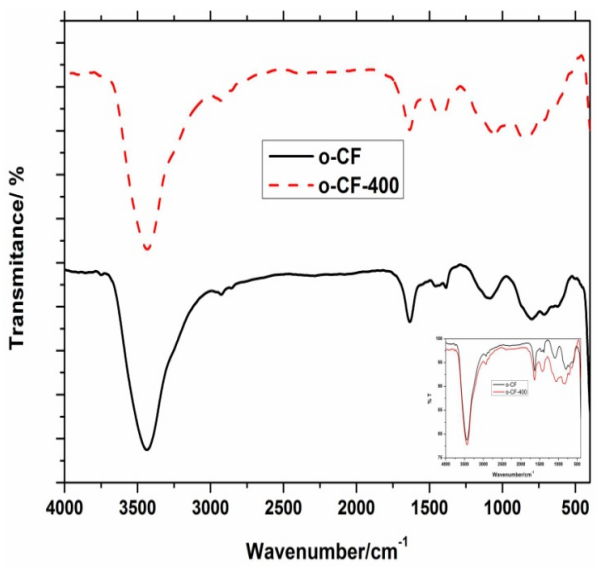

Fig. 3. FTIR spectra of the prepared CF samples.

Impact of initial $p$-NP concentration and contact time

Figure 5A shows comparative adsorption performances of both adsorbents. The adsorption uptake of $\mathrm{p}-\mathrm{NP}$ onto the surface of o-CF is higher than that of o-CF-400. This result is mainly owing to the porosity characteristics of o-CF where it possesses large surface area and high percentage of micropores as compared to that evolved in o-CF-400 (cf. Table 1). Hence, the adsorption of p-NP onto the prepared samples is clearly depended on the micropore surface area and micropore volume.

In order to examine the effect of both initial p-NP concentration and contact time on the adsorption capacity of the prepared o-CF sample, keeping all other parameters constant while the initial concentration of $\mathrm{p}-\mathrm{NP}$ and contact time were changed from 100 to $250 \mathrm{mg} / \mathrm{L}$ and from 10 to $180 \mathrm{~min}$ as shown in Fig. 5B, respectively. Thus when the contact time increased from 10 to $180 \mathrm{~min}$ and initial concentration of p-NP from 100 to 150 $\mathrm{mg} / \mathrm{L}$, the adsorption capacity was increased also until it reaches the equilibrium state at $\sim$ $45 \mathrm{~min}$. With $250 \mathrm{mg} / \mathrm{L}$, the p-NP molecules become more densely packed on the surface of adsorbent and hence the adsorption capacity is decreased while the equilibrium time is attained after long period $\sim 60 \mathrm{~min}$.

\section{Kinetic studies}

Figure $6(\mathrm{~A}-\mathrm{C})$ gives the representative

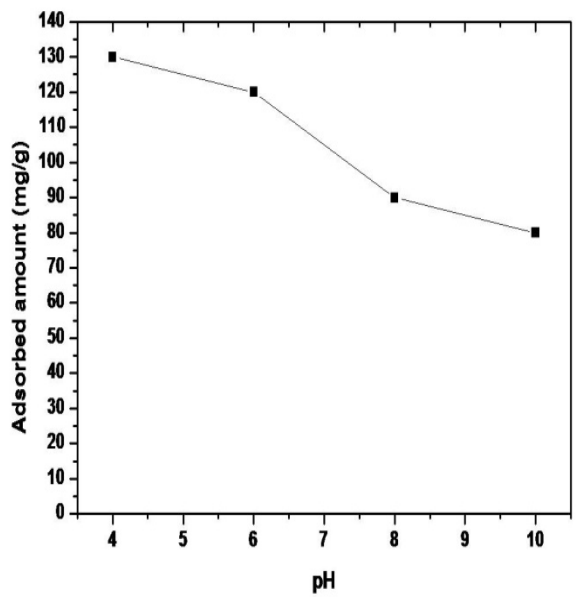

Fig. 4. Influence of initial $\mathrm{pH}$ on the adsorption amount of $\mathrm{p}$-NP using $0-\mathrm{CF}\left(\mathrm{C}_{0}=150 \mathrm{mg} / \mathrm{L}\right.$, carbon dose $=100 \mathrm{mg} / \mathrm{L}$, contact time $=120$ $\min$ and $\mathrm{T}=25^{\circ} \mathrm{C}$ ).

plots of kinetic models used for adsorption of $100 \mathrm{mg} / \mathrm{L}$ of $\mathrm{p}-\mathrm{NP}$ onto the o-CF sample at $25^{\circ} \mathrm{C}$ and $\mathrm{pH}$ 4. The kinetic adsorption constants derived from the corresponding models, i.e. pseudo-first-order, pseudo-secondorder and intraparticle diffusion, are listed in Table 2. Taking into account the corresponding correlation coefficients $\left(\mathrm{R}^{2}\right)$, the adsorption of $\mathrm{p}-\mathrm{NP}$ onto the prepared adsorbents were well-fitted with pseudo-second-order kinetic model. Furthermore, the experimental $q_{e}\left(q_{e}\right.$, ${ }_{\text {exp }}$ ) values are closer to the corresponding calculated values $\left(\mathrm{q}_{\mathrm{e}}\right.$, calc $)$ computed from the pseudo-second-order kinetic model, indicating that the overall process is both dependent on the amount of p-NP and on the available sites in the adsorbent.

The prevalence of intraparticle diffusion mechanism was estimated on adsorption of p-NP onto the o-CF sample. The intraparticle diffusion plots are shown in Fig. 6 C. Two linear plots were obtained as a result of adsorption of p-NP onto the o-CF sample. This confirms that adsorption process is not controlled only by this mechanism. Nevertheless, there are two-stages of adsorption including surface adsorption and intraparticle diffusion within the external pores in surface of the oxidized carbon fiber [30]. Finally, the adsorption of p-nitrophenol onto the prepared adsorbents was governed by both the external mass transfer and intraparticle diffusion mass transfer.

Egypt.J.Chem. 60 , No.6 (2017) 

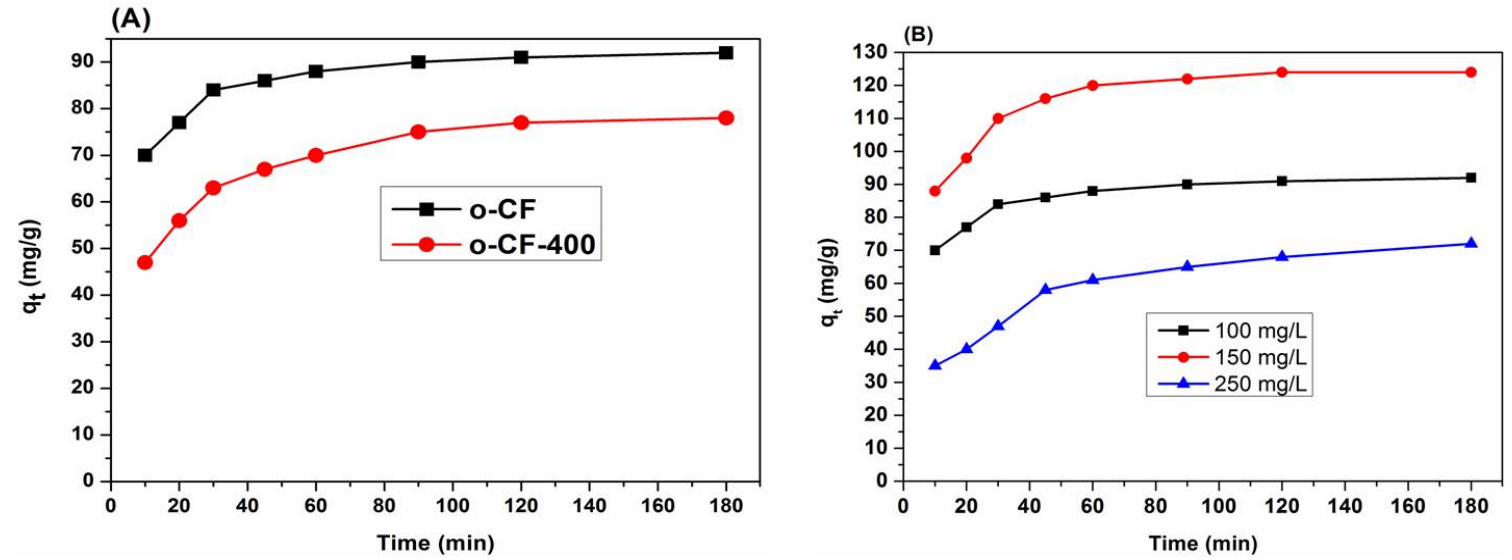

Fig. 5. (A) Adsorption of p-NP onto two adsorbents $\left(C_{0}=100 \mathrm{mg} / \mathrm{L}\right.$, carbon dose $=100 \mathrm{mg} / \mathrm{L}$, $\mathrm{pH}=4$ and $\left.T=25^{\circ} \mathrm{C}\right)$ and $(B)$ influence of initial $p$-NP concentration on the adsorption capacity of the $0-C F$ adsorbent (carbon dose $=100 \mathrm{mg} / \mathrm{L}, \mathrm{pH}=4$ and $\mathrm{T}=25^{\circ} \mathrm{C}$ ).
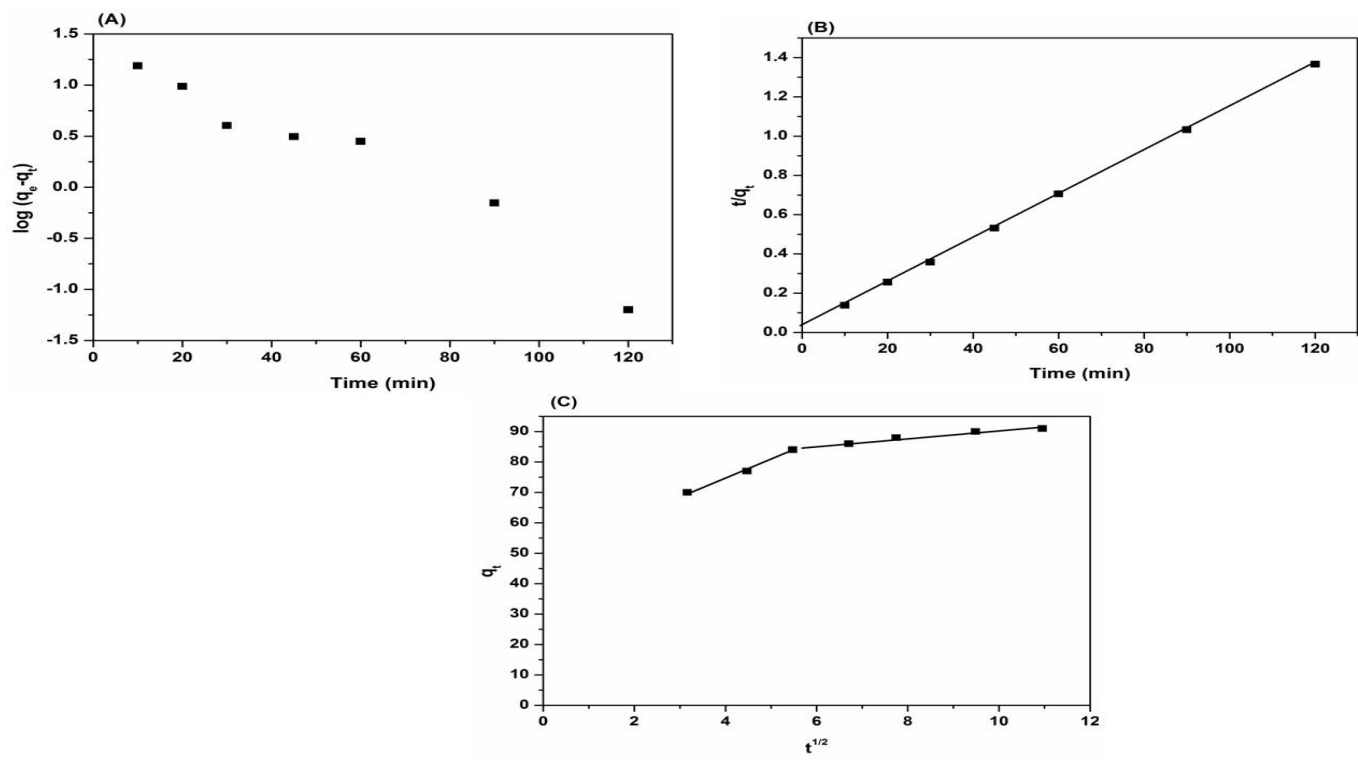

Fig. 6. Kinetic plots of (A) pseudo-first-order, (B) pseudo-second-order and (C) intraparticle diffusion obtained from kinetic adsorption of $\mathrm{p}-\mathrm{NP}$ onto the $\mathrm{o}-\mathrm{CF}$ sample $\left(\mathrm{C}_{0}=100 \mathrm{mg} / \mathrm{L}\right.$, carbon dose $=100 \mathrm{mg} / \mathrm{L}, \mathrm{pH}=4$ and $\left.\mathrm{T}=25^{\circ} \mathrm{C}\right)$.

TABLE 2. Kinetic parameters for p-NP adsorption at $25^{\circ} \mathrm{C}$ and $\mathrm{pH} 4$.

\begin{tabular}{|c|c|c|c|c|}
\hline \multirow{2}{*}{$\begin{array}{c}\text { Models } \\
\text { Pseudo-first-order }\end{array}$} & \multicolumn{3}{|c|}{ o-CF } & \multirow{2}{*}{$\begin{array}{l}0-C F-400 \\
100 \mathrm{mg} / \mathrm{L}\end{array}$} \\
\hline & $100 \mathrm{mg} / \mathrm{L}$ & $150 \mathrm{mg} / \mathrm{L}$ & $250 \mathrm{mg} / \mathrm{L}$ & \\
\hline $\boldsymbol{q}_{\text {e(exp) }}$ & 87 & 113 & 68 & 77 \\
\hline$k_{1}$ & 0.0453 & $5.5 \times 10^{-3}$ & 0.0122 & 0.0271 \\
\hline$q_{e(c a l c)}$ & 24.7 & 26.8 & 38.6 & 41.9 \\
\hline$R^{2}$ & 0.948 & 0.899 & 0.926 & 0.902 \\
\hline \multicolumn{5}{|l|}{ Pseudo-second-order } \\
\hline $\boldsymbol{k}_{2}$ & $4.37 \times 10^{-3}$ & $1.44 \times 10^{-3}$ & $4.61 \times 10^{-4}$ & $1.33 \times 10^{-3}$ \\
\hline$q_{e(c a l c)}$ & 89.2 & 116.3 & 79.4 & 80.6 \\
\hline $\boldsymbol{R}^{2}$ & 0.999 & 1 & 0.997 & 0.998 \\
\hline \multicolumn{5}{|l|}{ Intraparticle diffusion } \\
\hline $\boldsymbol{k}_{i d}$ & 1.78 & 1.84 & 3.53 & 3.50 \\
\hline$C_{i}^{\text {la }}$ & 70.5 & 90.1 & 24.6 & 39.8 \\
\hline
\end{tabular}

Egypt.J.Chem. 60 , No.6 (2017) 


\section{Equilibrium studies}

Linear form of three famous adsorption isotherms, viz. Langmuir, Freundlich and Temkin, was used to discuss how p-NP molecules are distributed between liquid and solid phases when the adsorption process reaches the equilibrium state, and to indicate the interaction level between an adsorbate and an adsorbent. The Langmuir model is generally supposed that the surface adsorption is entirely homogeneous; the Freundlich model is suitable for a heterogeneous system, and Temkin isotherm assumes that the adsorption heat of monolayer solute molecules (adsorbate) decreases linearly with an increase in the coverage due to interaction between adsorbate molecules.

The adsorption isotherms of p-NP onto obtained CF adsorbents are presented in Fig.7. For each isotherm, the uptake amount of p-NP molecules $\left(q_{e}, m g / g\right)$ increased with increasing equilibrium concentration as a result of driving force of adsorption that increased with increasing equilibrium concentration. Also, these isotherms are belonged to L-type. The calculated parameters from applying Langmuir, Freundlich and Temkin isotherms on the experimental adsorption data of $\mathrm{p}-\mathrm{NP}$ are listed in Table 3. The correlation coefficients $\left(\mathrm{R}^{2}\right)$ values, to measure the fitness of applied isotherms, reveals that the Langmuir model is the best to describe the adsorption of p-NP onto the prepared samples, confirming the homogeneity of active sites onto the microporous structure in the present oxidized CFs. Based on the cross-sectional area of $\mathrm{p}-\mathrm{NP}$ as mentioned earlier in [15], the adsorption capacity $(\mathrm{mg} / \mathrm{g})$ can be converted into surface area of p-NP covered the surface of both CF samples. It was noted that about $1 / 3$ of the total surface area is accessible to accommodate $\mathrm{p}$-NP molecules as listed in Table 3 . This result might be attributed to the competing adsorption of water molecules on pore openings and internal walls that reduces the sites available to $\mathrm{p}-\mathrm{NP}[15]$.

However, the adsorption capacity of o-CF is higher than that of the o-CF-400 by a factor of 1.66. The $q_{m}$ values obtained by application of Langmuir equation were 258 and $155 \mathrm{mg} / \mathrm{g}$ using o-CF and o-CF-400 adsorbents, respectively. The calculated negative values of $\Delta \mathrm{G}$ indicate the feasibility and spontaneous nature of adsorption of p-NP dye onto the materials obtained. The values of separation factor $\left(R_{\mathrm{L}}\right)$ show that the adsorption process of $\mathrm{p}$-NP onto carbon adsorbents is favorable $\left(0>R_{L}<1\right)$. The values of Freundlich constant $(1 / \mathrm{n})$ are lower than one for the adsorption of $\mathrm{p}-\mathrm{NP}$ onto the tested adsorbents showing that the adsorption process is also preferable.

Table 4 compares the adsorption capacities of different carbonaceous materials. The prepared oxidized carbon fiber sample has more or less adsorption capacity toward removal of $\mathrm{p}-\mathrm{NP}$ than that obtained by the other carbonaceous adsorbents. Due to its easy handling in filter system, thus the prepared oxidized fiber adsorbents can be used as potential adsorbents in removing organic pollutants from industrial wastewater.

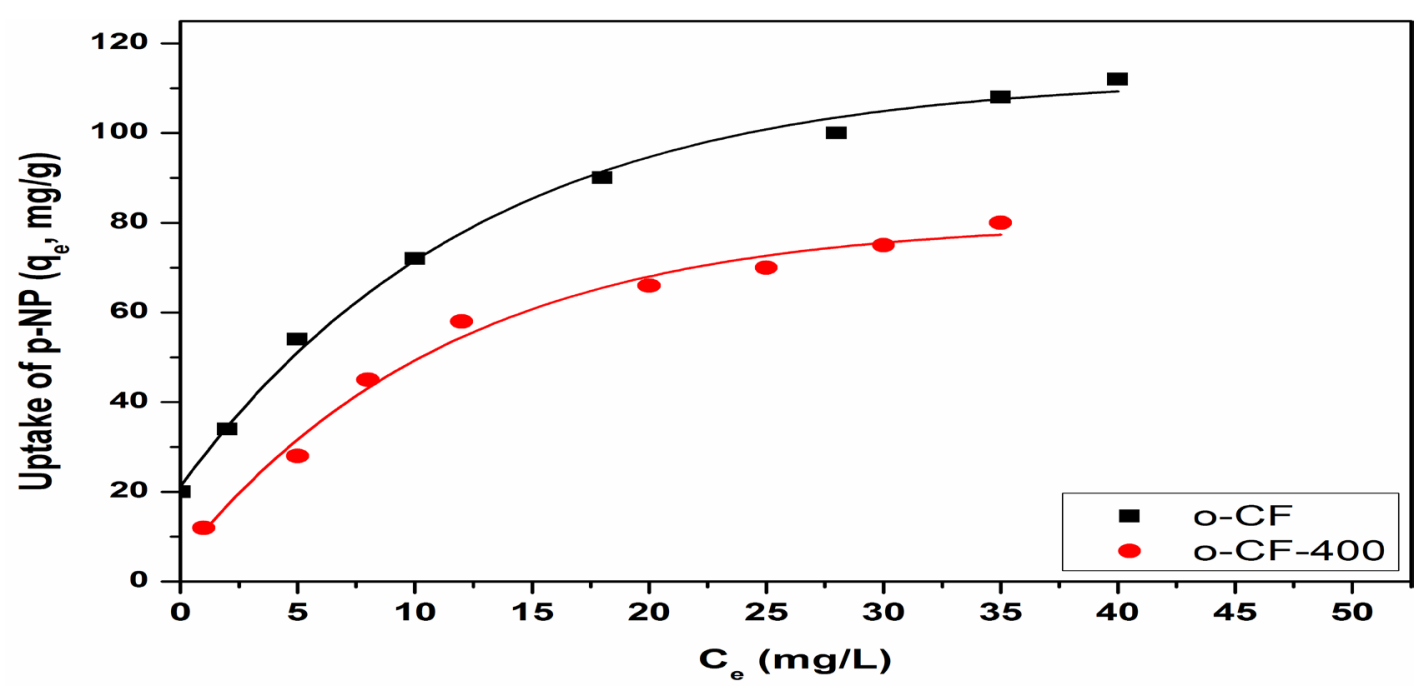

Fig. 7. Adsorption isotherms of p-NP onto oxidized CF adsorbents at 25oC and pH 4. 
TABLE 3. Langmuir, Freundlich and Temkin constants for adsorption of p-NP.

\begin{tabular}{|c|c|c|}
\hline Parameters & $\mathbf{0 - C F}$ & o-CF-400 \\
\hline \multicolumn{3}{|l|}{ Langmuir } \\
\hline $\mathrm{q}_{\mathrm{m}}(\mathrm{mg} / \mathrm{g})$ & 258 & 155 \\
\hline $\mathrm{K}_{\mathrm{L}}(\mathrm{L} / \mathrm{g})$ & 0.217 & 0.0399 \\
\hline$\Delta \mathrm{G}^{\circ}(\mathrm{kJ} / \mathrm{mol})$ & -25.5 & -21.3 \\
\hline $\mathrm{R}^{2}$ & 0.998 & 0.995 \\
\hline Area covered by $\mathrm{p}-\mathrm{NP}\left(\mathrm{S}_{\mathrm{p}-\mathrm{NP}}, \mathrm{m}^{2} / \mathrm{g}\right)$ & 575 & 346 \\
\hline $\mathrm{S}_{\mathrm{p}-\mathrm{NP}} / \mathrm{S}_{\mathrm{BET}}(\%)$ & 37.7 & 30.5 \\
\hline \multicolumn{3}{|l|}{ Freundlich model } \\
\hline $\mathrm{K}_{\mathrm{F}}(\mathrm{mg} / \mathrm{g}) /(\mathrm{L} / \mathrm{mg})^{1 / n}$ & 18.8 & 2.08 \\
\hline $1 / \mathrm{n}$ & 0.422 & 0.731 \\
\hline $\mathrm{R}^{2}$ & 0.855 & 0.955 \\
\hline \multicolumn{3}{|l|}{ Temkin model } \\
\hline $\mathrm{B}$ & 127 & 37 \\
\hline $\mathrm{K}_{\mathrm{T}}(\mathrm{J} / \mathrm{mol})$ & 1.18 & 2.91 \\
\hline $\mathrm{R}^{2}$ & 0.874 & 0.948 \\
\hline
\end{tabular}

TABLE 4. Comparison of the adsorption capacity $\left(q_{m}, \mathrm{mg} / \mathrm{g}\right)$ of different carbonaceous adsorbents toward adsorption of $\mathrm{p}-\mathrm{NP}$.

\begin{tabular}{ccc}
\hline Carbonaceous adsorbents & $\mathbf{q}_{\mathbf{m}}(\mathbf{m g} \mathbf{g})$ & Ref. \\
\hline Oxidized carbon fiber & 258 & This study \\
Activated carbons & 212 & {$[10]$} \\
Reduced-graphene oxide & 500 & {$[11]$} \\
oxidized single-walled carbon nanotubes & 206 & {$[12]$} \\
Active carbon fiber & 385 & {$[14]$} \\
Treated activated carbons & 225 & {$[30]$} \\
\hline
\end{tabular}

\section{Conclusions}

In summary, feasible carbon fiber adsorbent were prepared and characterized by techniques such as SEM, FTIR, Boehm's titration and porosity development using $\mathrm{N}_{2}$ gas adsorption at $-196^{\circ} \mathrm{C}$. Kinetic and equilibrium adsorption studies were investigated using p-nitrophenol as a model organic compound. It can be found that the two samples obtained are most probably containing acidic oxygen functional groups. The pseudo-second-order kinetic model fitted very-well with the adsorption data of $\mathrm{p}$-NP and the intraparticle diffusion is not the only ratecontrolling step. The equilibrium adsorption results well- described by the Langmuir isotherm than by other models. The $q_{m}$ values obtained by application of Langmuir equation were 258 and $155 \mathrm{mg} / \mathrm{g}$ using o-CF and o-CF-400 adsorbents,

Egypt.J.Chem. 60 , No.6 (2017) respectively. In conclusion, the prepared oxidized CFs can be used as promising adsorbents for removing organic pollutants from wastewater.

\section{Acknowledgement}

The authors gratefully acknowledge the financial support provided by the National Research Centre (NRC), Egypt, under the Project No. 11090201.

\section{References}

1. ATSDR, Toxicological Profile for Nitrophenols: 2-Nitrophenol and 4-Nitrophenol, Public Agency for Toxic Substances and Disease Registry, Health Service(1992).

2. USEPA, National Pesticide Survey: 4-NitroPhenol, National Service Center for Environmental Publications, 2015 (2017). 
3. U.S.EPA, 4-Nitrophenol, in: H.a.E.E.P.N. 135 (Ed.), Government Printing Office, District of Columbia, U.S.(1980).

4. Liu F., Wu Z. ,Wang D., Yu, J., Jiang, X. and Chen, X., Magnetic porous silica-graphene oxide hybrid composite as apotential adsorbent for aqueous removal of p-nitrophenol. Colloids Surf. A: Physicochem.Eng. Aspects 490, 207-214 (2016).

5. Fathy N.A., Shouman M. A. and Aboelenin R.M.M., Nitrogen and phosphorous-doped porous carbon xerogels as metal-free catalysts for environmental catalytic peroxide oxidation of 4-nitrophenol. Asia-Pac. J. Chem. Eng. 11, 836845 (2016)

6. Rodrigues C.S.D., Soares O.S.G.P., Pinho M.T. , Fernando M., Pereira, R. and Madeira, Luis M., p-Nitrophenol degradation by heterogeneous Fenton's oxidation over activated carbon-based catalysts. Applied Catalysis B: Environmental 219, 109-122 (2017).

7. Martín-Hernández, M. Suárez-Ojeda, M.E. and Carrera, J., Bioaugmentation for treating transient or continuous p-nitrophenol shock loads in an aerobic sequencing batch reactor. Bioresour. Technol. 123, 150-156. (2012).

8. Zagklis, D.P., Vavouraki, A.I., Kornaros, M.E. and Paraskeva, C.A., Purification of olive mill wastewater phenols through membrane filtration and resin adsorption/desorption. J. Hazard. Mater. 285, 69-76.(2015)

9. Qu X., Tian, M., Liao B. and Chen A., Enhanced electrochemical treatment of phenolic pollutants by an effective adsorption and release process. Electrochim. Acta 55, 5367-5374 (2010).

10. Fathy, N. A., Ahmed, S. A. S., and Aboelenin, R. M. M., Effect of activation temperature on textural and adsorptive properties for activated carbon derived from local reed biomass: Removal of p-nitrophenol. Environ. Res. Eng. Manag. 1 (59), 10-22, (2012).

11. Fathy N. A., Abd El-Latif R. R., Aboelenin, R. M. M. and Khalil L. B., Green reduction of oxidized graphite to reduced graphene oxide using Zygophyllum album L.f.: Comparative adsorption studies on p-nitrophenol,.RICE 8, 87 - 102. (2015).

12. Yao, Y.-X., Li H.B., Liu J.-Y., Tan X.-L., Yu J.-G. and Peng Z.-G., Removal and adsorption of p-nitrophenol from aqueous solutions using carbon nanotubes and their composites, J. Nanomaterials 2014 1-9 (2014)

13. Ayranci, E. and Duman, O., Adsorption behaviors of some phenolic compounds onto high specific area activated carbon cloth, J. Hazard. Mater. B124,125-32 (2005).

14. Tang, D., Zheng, Z., Lin.K., Luan, J. and Zhang, J. Adsorption of $p$-nitrophenol from aqueous solutions onto activated carbon fiber, J. Hazard. Mater. 143, 49-56 (2007)

15. Attia, A.A., Girgis, B.S. and Khadr, S.A. Capacity of activated carbon derived from pistachio shells by $\mathrm{H}_{3} \mathrm{PO}_{4}$ in the removal of dyes and phenolics, J. Chem. Technol. Biotechnol. 78, 611-19(2003)

16. Daifullah A.A.M. and Girgis B.S., Removal of some substituted phenols by activated carbon obtained from agricultural waste. Water Res. 32, 1169-1177 (1998).

17. Hearle, J.W.S. High-performance Fibres, Woodhead, Cambridge, UK (2001).

18. Masson JC, Acrylic Fiber Technology and Applications, Marcel Dekker, New York (1995).

19. IUPAC in Recommendations for the characterization of porous solids (Technical Reports). Pure Appl. Chem. 66, 1739 (1994).

20. Selles-Perez, M.J. and Martin-Martinez, J.M. J. Chem. Soc. Farad. Trans. 87, 1237. (1991).

21. Ravikovitch P.I. and Neimark Alexander V., Experimental confirmation of different mechanisms of evaporation from ink-bottle type pores: Equilibrium, pore blocking, and cavitation, Langmuir, 18 (25), pp 9830-9837.(2002).

22. Boehm H.P., Surface oxides on carbon and their analysis: A critical assessment. Carbon 40, 145149 (2002).

23. Lagergren, S. Zur theorie der sogenannten adsorption geloster stoffe. 591. Kungliga Svenska Vetenskapsakademiens. Handlingar 24, 1-39 (1898).

24. Ho Y.S. and McKay G., Sorption of dye from aqueous solution by peat. Chem. Eng. J. 70, 115124. (1998).

25. Weber, W.J. and Morris, J.C. Kinetics of adsorption on carbon from solution, J. Sanit. Eng. Div. Am. Soc. Civ. Eng. 89, 31-60(1963).

26. Langmuir, I., The adsorption of gases on plane Egypt.J.Chem. 60 , No.6 (2017) 
surfaces of glass, mica and platinum. J. Am. Chem. Soc. 40, 1361-1403 (1918).

27. Freundlich, H.M.F. Over the adsorption in solution. J. Phys. Chem. 57, 385-470 (1906).

28. Temkin, M.I. and Pyzhev, V. Kinetic of ammonia synthesis on promoted iron catalyst, Acta Phys. Chem. URSS 12, 327-356 (1940)

29. Pamula, E. and Rouxhet, P.G. Bulk and surface chemical functionalities of type III PAN-based carbon fibres. Carbon 41, 1905-1915. (2003).

30. Nouri, S. and Hagheseresht, F. Adsorption of p-nitrophenol in untreated and treated activated carbon, Adsorption, 10, 79-86 (2004).

(Received $22 / 10 / 2017$

accepted 15/11/2017)

\title{
ازالة البارا- نيتروفينول من محاليل مائية باستخدام الياف الكريون المؤكسدة
}

شيماء السيد الثافعى، نادي عطية فتحي، ليلي بولس خليل الئيل

معمل كيمياء السطوح و الحفز ـ قسم الكيمياء الفيزيقية ـ المركز القومى للبحوث ـ الجيزة ـمصر.

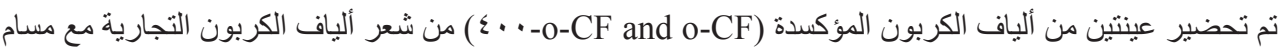

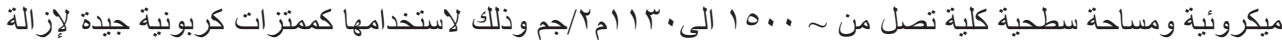

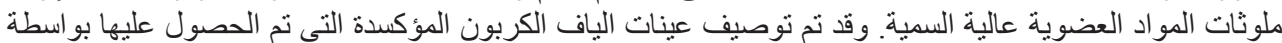

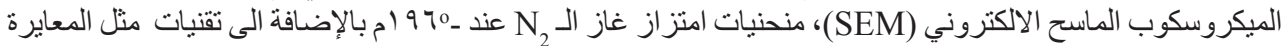

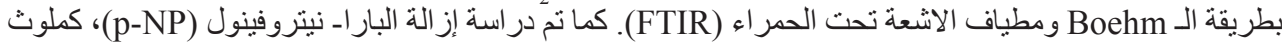

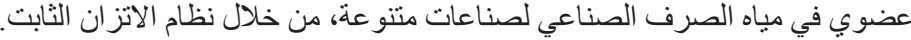

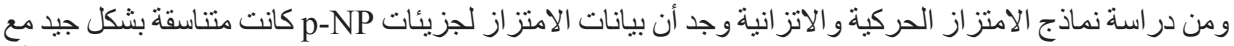

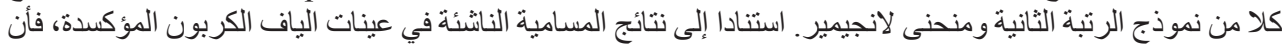

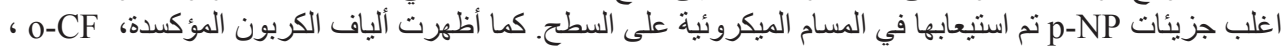

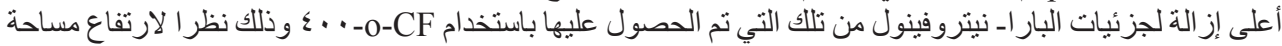

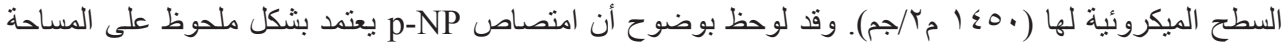

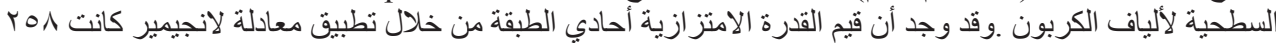

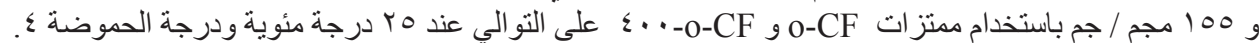

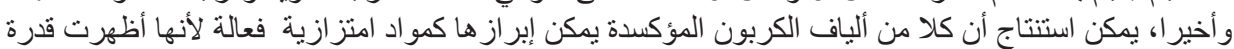

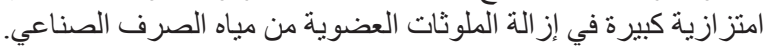

